\title{
Role of Work-Family Conflict in Job Burnout: Support from the Banking Sector of Pakistan
}

\author{
Syed Harris Laeeque \\ Department of Management Sciences, Bahria University, Islamabad, Pakistan \\ E-mail address: harris970@live.com
}

\begin{abstract}
The main aim of this study is to determine the relationship between work-family conflict (WFC) and job burnout experienced by an employee. This study follows a cross-sectional and quantitative approach. Self-administered, ordinal scale based questionnaires are used as an instrument to collect the responses from 200 respondents, working in the head offices of two private banks in Islamabad, Pakistan. Kendall tau-b rank correlation coefficient, linear regression and one-way ANOVA are employed for testing conceptual and mathematical model. The results of statistical analysis shows that both the domains of work-family conflict i.e. family interference with work and work interference with family, significantly and positively influence the job burnout of employees. Organizations must take an initiative to resolve the work-family conflict so that the employees devote their full capacity to work and also be able to meet their family requirements easily.
\end{abstract}

Keywords: Work-family conflict; family interference with work; work interference with family; job burnout

\section{INTRODUCTION}

Since the past three decades, the working atmosphere has witnessed a radical change globally. In past the timings for job were limited to 9 am to $5 \mathrm{pm}$. Fixed work was assigned to everyone with no supplementary responsibilities. However, now the circumstances have changed completely with globalization. The days of 9 to 5 have gone, instead the working hours are now around 12 to 15 hours per day. The workplaces are often located on the suburbs of cities which increases the time required for travelling. Technological progressions are a gain for work, but have gradually become a nuisance for the workers during their private time. Getting official calls, SMS, and emails have made the people feel as if they are functioning as employees even at home. This is how the notion of work-family conflict (WFC) has surfaced (Sao, 2012).

Work-family conflict (WFC) is a type of inter-responsibility clash in which the responsibility demands from the occupational and family spheres are unable to mutually coexist - in such manner that involvement in the occupational (or family) role is made additionally hard by virtue of involvement in the family (or occupational) role (Greenhaus \& Beutell, 1985). This definition proposes a bidirectional facet in which the sphere of work can meddle with the sphere of family and vice versa (Koekemoer \& Steyl, 2011). Research on the subject of workfamily conflict has stretched out massively over the past three decades owing to the variations 
in workforce composition and workplaces. The invasion of women into the labor force and the associated rise of dual-income couples, as well as a boost in single-parent families, has contributed to a craving to better comprehend work-family divergence (Hammer et al., 2009; Kossek \& Lambert, 2005; Neal \& Hammer, 2007).

Pakistan is a developing nation with a labor force of about 57.24 million people. According to the Labor Force Survey report of 2012-13, labor force participation rate was about $32.8 \%$; an increase of $3.2 \%$ over 10 years. During the year 2012-2013, the labor force participation rate was $49.3 \%$ for men, as compared to $47.6 \%$ during $1999-2000$; and $15.6 \%$ for women, as compared to only $9.3 \%$ during 1999-2000. On the average the employed Pakistanis work for 46.57 hours a week; males work for 50.06 hours, while, females work for 33.45 hours a week. This scenario shows that more and more people are joining the labor force every year to meet their personal and family responsibilities and to make both ends meet. Sadly in Pakistan work-life conflict is generally being ignored by many organizations as there is not adequate research done in this domain. In Pakistan organizations usually are relate the employees' performance with variables like pay, compensations, motivation, training and etc. (Ashfaq, Mahmood, \& Ahmad, 2013).

Work-family conflict is a hot issue across the globe. It is a problematic matter for both, the employee and the organization. On one hand WFC negatively influences the employees' wellbeing, job satisfaction, commitment, and performance; on the other hand due to WFC, organizations fail to utilize the skills and abilities of employees to their full potential. An increasing number of people in Pakistan are complaining of job burnout as they are unable to manage their work and family obligations simultaneously.

This research has three broad objectives: (1) to develop the understanding of work-family conflict by considering its constructs, insights, strengths, weaknesses and validity; (2) to determine the role of work-family conflict in the job burnout experienced by an employee; and (3) to assist the management in bringing changes in the workplace in order to resolve the workfamily conflict experienced by employees.

\section{LITERATURE REVIEW}

When there is a disturbance in the family and work life of a worker or he/she has to perform conflicting roles, then overall productivity of the employee and also of the organization is disrupted. Hence this matter is of immense significance for both the employee, and firm as a whole. Labor is the most valuable asset of any organization for the reason that all other resources are dependent on labor for their appropriate utilization (Aslam et al., 2011). The work-family conflict increases as we move upwards in the managerial hierarchy. This may be due to the fact that senior workers do jobs that place great responsibilities on their shoulders. As a result they often take their work home and may feel that their family obligations hinder the fulfillment of their tasks (Patel et al., 2006).

According to Wang et al. (2012), work-to-family and family-to-work conflict was positively associated with emotional fatigue and cynicism, respectively, among Chinese nurses. WFC was positively linked to professional efficacy while FWC was negatively associated with it. In her study, Tabassum (2012) had proposed and analyzed a research model that attempted to investigate the relationship of social support on work-family conflict. The results of her study revealed that spouse and family cooperation were negatively allied with work-family conflict however no negative association was noticed between supervisor and colleague support and work-family conflict. Sharafi and Shahrokh (2012) made a unique attempt to examine whether 
there was a relationship between the suffering of work-family conflict by an employee and its effects on a co-worker's turnover intention. They said that today's jobs are often structured in departments and teams, wherein the workers frequently interact with each other and share their personal and professional plights. In such work settings where co-workers closely collaborate, it is probable that the WFC faced by one worker may hinder the performance of a co-worker.

Ahmad and Omar (2010) examined the mediating character of work-family conflict in the association between organizational culture and job stress faced by a worker. They found that employees who observed that there was an existence of a family-supportive culture in the workplace, characterized by high sensitivity to work-family issues, were less likely to experience job stress, and went through an enhanced work-family balance. To investigate the mediating influence of work-family conflict (WFC) on the association between role burden and emotional overtiredness, Ahmad (2010) collected data from 220 Malaysian female low-grade physicians. He concluded that low-grade physicians who suffered role burden were more probable to become emotionally shattered and seemed to encounter more divergence between the work and family responsibilities.

Ahmad and Ngah (2011) inspected the indirect outcomes of dispositional factors on work satisfaction via work-family clash using a sample of 159 single mother workers. The results revealed that professional precision and locus of command were major individual assets that were linked to work-family conflict and job satisfaction experienced by a worker. Ngah, Ahmad and Baba (2009) studied the mediating role of work-family conflict within the connection between locus of command and work satisfaction. The results of their study showed that single mother staff whose internal locus of command was high, had a lower propensity to experience work-family conflict. This would consecutively increase their degree of job satisfaction.

Ismail et al. (2012) performed a study to scan the association between the humanistic social support from workplace and work-family conflict. The results explained that the willingness of supervisors and colleagues to sufficiently present material and moral cooperation in performing jobs had lessen the work-family conflict faced by workers. Knecht a et al. (2011) conducted a longitudinal study to examine the rapport between work-family conflict and the wellbeing and healthiness of workers. They found that work-life clash was very much correlated with health satisfaction. Conversely, no confirmation was found for a continual work-life clash escorting to poor wellbeing satisfaction. Koekemoer and Steyl (2011) performed a study on African mining industry and they asserted that there were noteworthy disparities for marital status and the language groups about work-family inconsistency. Their findings showed that respondents who primarily spoke African languages faced elevated levels of family-work conflict.

In their study, Zhang and Liu (2010) attempted to identify the probable effects of personal aspects (such as demographic and individuality variables), job variables (like job stress, family responsive programs), and family variables (such as family require and spousal relations) on the work-family conflict/balance. On the basis of her results, Anafarta (20011) claimed that there was a reciprocal link between WFC and FWC and that WFC had an authority on determining job satisfaction while FWC did not have an effect on job satisfaction. Beauregard (2006) claimed that it was natural and widespread to witness that the extra time spent in the job sphere unavoidably resulted in fewer time on hand to be spent at the home domain, making it exceedingly difficult to meet the family obligations. From the study of Alam, Sattar and Chaudhary (2011) conducted in Dhaka, it was exposed that prolong office hours influenced work family balance straightforwardly and offsprings were the most awful sufferers of this WFC. 
Result of the analysis of Komarraju (2006) put forward that dual-career workers who experienced their family commitments interfering into their job activities were likely to face job dissatisfaction. Dual-career workers who got backing and assistance from a spouse or workplace were more prone to experience improved job satisfaction. Anafarta and Kuruüzüm (2012) stated that the degree of WFC experienced by both men and women was soaring, and there was no statistically significant difference between their averages. In both men and women, the WFC was negatively associated with education. However, in men WFC was negatively related with marital status whereas, in women it was positively related with it.

Namayandeh, Juhari and Yaacob (2011) concluded that WFC among wedded female nurses in Shiraz (Iran) was associated with work satisfaction and family unit satisfaction. Conversely, FWC was not allied to the work satisfaction but was related to family unit satisfaction. Nadeem and Abbas (2009) found from their research that occupational strain coupled with work life conflict resulted in variation in the work satisfaction of the workers. Work to family intervention, family to work intervention and strain were negatively connected with work satisfaction. Job independence and work burden was positively related with job satisfaction. The relation between work-family conflict and the big five individuality model was investigated by Blanch and Aluja (2009) and it was uncovered that work requirement, work and family unit encouragement and neuroticism were the most crucial factors which meddled with work life conflict. Noor and Maad (2008) looked at the association between work-family conflict, strain and turnover intentions experienced by Pakistani employees working in marketing area. They found that work-family conflict and strain had positive liaison with employees' turnover intentions.

Malik et al. (2010) observed the relationship between work life balance and job contentment among the Pakistani MBBS doctors and found no major effects of work life balance on job contentment. According to the results found by Albertsen et al. (2008) the association between greater numbers of working hours and lesser levels of work-life balance was ardently supported among women. However for men, the findings were less convincing. They found compelling indication that nonstandard working hours had a negative impact on work-life balance and also found some confirmation that it had an unconstructive effect on children's welfare and on marital happiness.

\section{1. Conceptual and mathematical model}

The proposed conceptual model for hypotheses testing is as follows:

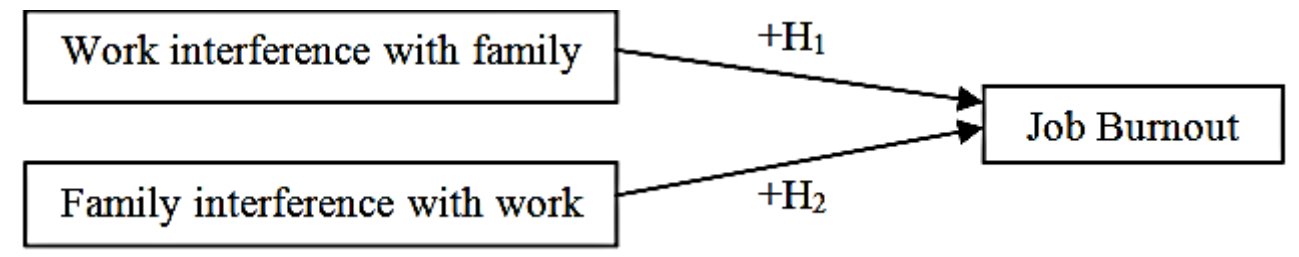

Figure 1. Theoretical model.

$\mathrm{H}_{1}$ and $\mathrm{H}_{2}$ represent the two hypotheses of this study and the positive $(+)$ sign indicates the direction of the relationship. 'Work interference with family' and 'family interference with work' are the independent variables of this study; while 'job burnout' is the dependent variable.

The mathematical model for this study is exhibited below: 


$$
\mathrm{Y}=\alpha+\beta_{1} \mathrm{WIF}+\beta_{2} \mathrm{FIW}+\mu
$$

Where, Y represents 'job burnout', $\alpha$ represents the intercept (value of $Y$ when WIF or FIW is zero), $\beta_{1}$ and $\beta_{2}$ are the slope coefficients for WIF and FIW respectively, and $\mu$ symbolizes the stochastic/unknown factors.

\section{2. Hypotheses}

This study attempts to test the following two hypotheses which have been adopted from the work of various researchers (Wang et al., 2012; Carlson et al., 2012; Lambert \& Hogan, 2010; Montgomery et al., 2006; Thanacoody et al., 2009):

$\mathbf{H}_{1}$ : There is a positive relationship between work interference with family (WIF) and job burnout.

H2: There is a positive relationship between family interference with work (FIW) and job burnout.

\section{METHODOLOGY}

Research Methodology entails the process and manner that determine how information is collected and examined (Gordon, 1998). The methodology of this study is discussed under the following broad headings:

\section{1. Research Design}

This is a pure, empirical, survey-based field study which is conducted with minimal interference by the researcher. It is a causal study as it attempts to investigate the effect of workfamily conflict on job burnout. It is cross-sectional in nature as the data was collected within two days.

\section{2. Procedure and Participants}

This study employs multistage sampling technique to select the sample. First, the banking sector was selected from the service industry of Pakistan. Then, among all the banks, two private banks were randomly chosen and their head offices in Blue Area, Islamabad were targeted. Finally, out of all the employees working in these offices, 100 employees were randomly selected from each bank; making a total sample size of 200 respondents. To facilitate data collection, ordinal scale based questionnaires were self-administered in the first week of June 2013.

The questionnaire consisted of 35 questions and was divided into 6 parts. After rejecting incomplete questionnaires, total 163 usable questionnaires were achieved, ensuing in a response rate of $81.5 \%$.

\section{3. Characteristics of the sample}

The mean age of the sample was 32.33 years $(\mathrm{SD}=6.965)$. Out of the total respondents, $69.9 \%$ were males, whereas $30.1 \%$ were females. $52 \%$ of respondents had done Masters, whereas $46 \%$ had Bachelor's degree. $37 \%$ of the respondents were single, $60 \%$ were married, while 3\% had other marital statuses (such as divorced, separated, or widowed). $41 \%$ of the respondents had no children, $53 \%$ had 1 to 3 children, while $7 \%$ had more than 3 children. The 
average working experience of the respondents was 11.50 years $(\mathrm{SD}=5.845)$. Mean time the respondents daily spend with their families was 3.60 hours $(\mathrm{SD}=1.317)$ and the mean daily working hours were 9.82 hours $(\mathrm{SD}=1.401)$.

\section{4. Measurement}

Work-family conflict (WFC) was measured through two subscales, family interference with work (FIW) scale and work interference with family (WIF) scale. Both these subscales have been adopted from the work of Netemeyer, Boles, \& McMurrian (1996). Each subscale consisted of 5 items; all items were measured through a five-point Likert scale varying from 'strongly agree' (1) to 'strongly disagree' (5).

The scale to measure job burnout was inspired from Maslach Burnout Inventory- General Survey (MBI-GS), developed by Maslach and Jackson (1981). The researcher of this study took help from MBI-GS and designed a new scale, keeping in mind the cultural and attitudinal dimensions of Pakistani employees. The job burnout scale consisted of three subscales, namely (1) emotional exhaustion, (2) professional efficacy, and (3) cynicism. Each subscale consisted of 5, 6, and 5 item respectively; scored on a five-point Likert scale varying from 'never' (1) to 'everyday' (5).

\section{5. Scale reliability}

Cronbach's alpha coefficient was applied to facilitate the measurement of reliability of the collected data. It verifies the correlation among all variables in the scale (Sharafi \& Shahrokh, 2012). Cronbach (1951) recommends that the minimum value for reliability should be 0.7. The table below demonstrates the Cronbach's alpha coefficient for all variables in the questionnaire. In this study the Cronbach's alpha for all the scales exceed the minimum level of reliability.

Table 1. Scale validity and reliability.

\begin{tabular}{|c|c|c|c|c|c|c|}
\hline Scale & Alpha & Subscale & Items & Mean & SD & Alpha \\
\hline $\begin{array}{c}\text { Work- } \\
\text { family } \\
\text { conflict }\end{array}$ & 0.884 & Work interference with family & 5 & 2.72 & 1.06 & 0.855 \\
\cline { 3 - 7 } & Family interference with work & 5 & 2.88 & 0.98 & 0.757 \\
\hline \multirow{2}{*}{$\begin{array}{c}\text { Job } \\
\text { Burnout }\end{array}$} & 0.941 & Emotional exhaustion & 5 & 2.77 & 1.15 & 0.906 \\
\cline { 3 - 7 } & & Professional efficacy & 6 & 2.81 & 1.02 & 0.852 \\
\cline { 3 - 7 } & & Cynicism & 5 & 2.90 & 0.92 & 0.773 \\
\hline
\end{tabular}

\section{6. Statistical analysis}

The data gathered through questionnaires was analyzed through SPSS 20.0 program and all statistical tests were two-tailed. Descriptive statistics were utilized to illustrate the main characteristics of the sample. Kendall's Tau-b rank correlation coefficient was used to measure the non-parametric association between the variables. It assesses the association between ordinal variables while taking tied ranks into account (Hinton, Brownlow \& McMurray, 2004). 
The study also applied linear regression and one-way ANOVA to examine how strongly the independent variable predicts or explains the variations in the dependent variable.

\section{RESULTS}

The Kendall tau-b correlation test statistic for the association between work interference with family and job burnout is +0.695 ; signifying a strong correlation. Similarly the Kendall tau-b correlation coefficient for the relationship between family interference with work and job burnout is +0.338 ; indicating a weak correlation between the variables. The ${ }^{* *}$ with this statistic signifies that it is significant at the 0.01 level for a one-tailed prediction. The sign of the correlation statistics indicate positive relationships between the variables in the model. As the WIF or FIW increases or decreases, the job burnout experienced by the employee also increases or decreases in the same direction.

Table 2. Correlations among study variables.

\begin{tabular}{|c|c|c|c|c|c|}
\hline & WIF & FIW & JB & Mean & SD \\
\hline Work interference with family & 1 & & & 2.718 & 1.0660 \\
\hline Family interference with work & $0.235^{* *}$ & 1 & & 2.876 & 0.978 \\
\hline Job burnout & $0.695^{* *}$ & $0.338^{* *}$ & 1 & 2.823 & 0.968 \\
\hline
\end{tabular}

Table 3. Regression analysis.

\begin{tabular}{|c|c|c|c|c|}
\hline & Beta & Std. Error & $\mathrm{t}$ stat & Significance \\
\hline Job burnout & .560 & .136 & 4.111 & .000 \\
\hline Work interference with family & .842 & .034 & 24.618 & .000 \\
\hline Family interference with work & .124 & .043 & 2.912 & .004 \\
\hline
\end{tabular}

Note. $\mathrm{R}=0.911, \mathrm{R}$ square $=0.830, \mathrm{~F}=391.313, p<0.01, \mathrm{~N}=163$.

The $\mathrm{R}$ square $=0.830$ shows that $83 \%$ of the total variation in the job burnout can explained by WIF and FIW. The remaining $17 \%$ of variation in the job burnout level is due to the stochastic factors. As 0.830 is a large number, it can be confidently claimed that WIF and FIW are true predictors of job burnout experienced by an employee. The $\mathrm{F}$ value $=391.313$ at $p<0.01$, which shows that the overall significance of the model is very high; the variables included in the model are very much pertinent, and play a significant role in predicting the dependent variable (job burnout).

The beta coefficient shows that for 1 unit change in WIF, the job burnout increases by 0.842 units; it also increases by 0.124 units for every 1 unit increase in FIW. The $t$ stat measures the relative strength of prediction. The $t$ values for WIF and FIW are 24.618 and 2.912 respectively; demonstrating the significance and validity of these variables in the model. The 
high $t$ stat of both the independent variables (WIF and FIW) explains that the statistical theory provide strong support on their influence on job burnout experienced by employees. Hence, it is concluded that both the hypotheses of this study are supported by the results. The mathematical model of this study now takes the following shape:

Job burnout $(\mathrm{Y})=0.560+0.842(\mathrm{WIF})+0.124(\mathrm{FIW})+\mu$

\section{CONCLUSIONS}

This study intended to measure the relationship between the two dimensions of workfamily conflict (i.e. WIF and FIW) and job burnout experienced by an employee. Through the help of statistical test it is suggested the employee whose involvement in the work domain interfere with his/her family life (WIF) is likely to experience job burnout. Similarly, the employee whose experiences in family domain hinder his/her contribution in work life (FIW) is very prone to suffer job burnout. The results also showed that both these dimensions of workfamily conflict are significantly correlated with each other too.

This study will raise awareness in the management about the possible consequences of work-family conflict on employee behavior and performance. It will provide an opportunity to the management to better understand the employees. The present study will also guide the management in utilizing the capabilities of employees to their utmost potential. This is the first study in Pakistan which attempts to explore the relationship between WFC and job burnout. So it will facilitate the practitioners to conduct researches in this domain by serving as a guideline or a basis for critique for future studies.

\section{Limitations}

This study is subject to few limitations such as: (1) due to the time and budget restrictions this study is kept cross-sectional; (2) the sample of this study is restricted only to Pakistan therefore comparing results across different nations is not possible; (3) owing to the small sample size this study is low on precision and validity, and the results may lack generalizability; (4) this is an entirely survey based research and questionnaire is the only instrument for collecting the data; and lastly (5) the respondents might have misinterpret the questions by not understanding them fully, or they might not have taken them seriously.

\section{Recommendations}

If the companies wish to resolve the work-family conflict faced by their employees, they should consider the following two suggestions:

First suggestion is that flexplace (flexible location of work) and flextime (flexible work timings) approach should be introduced by the organizations to facilitate the minimization of which work-family conflict. Flexplace incorporates telecommuting, through which employee get an opportunity to work from any another setting, usually his/her home. Flexplace also incorporates virtual office, through which an employee can execute their job at anytime and anywhere it makes sense, by using portables means given by the employer. Flextime is the rearrangement of paid work time of employees.

Second suggestion is that organizations should provide support, cooperation and counseling services to employees who face difficulty in meeting the demands of family, work, or both. Through family-caring policies, coordinative supervisory practices and family oriented remuneration or outcomes, organizations can resolve the work-family conflict of its employees 
to a large extent. Family oriented benefits (such as child care program, maternity leave, etc.) can play an important role in motivating the employees who are suffering from heavy work overload, demanding work schedule and intrusive family related obligations.

There are certain considerations for future research in this domain such as: (1) there is a need for longitudinal research which could probe into the behavioral changes in employees over time; (2) the sample size should be enlarged in order to increase the generalizability of results; (3) instead of relying on a survey based quantitative research, other methods of research should be used such a triangulation technique; and (4) a diverse sample should be made from organizations in different industries.

\section{References}

[1] Ahmad, A. (2010). Work-family conflict among junior physicians: Its mediating role in the relationship between role overload and emotional exhaustion. Journal of Social Sciences, 6(2), 265-271.

[2] Ahmad, A., \& Ngah, N. (2011). Impact of dispositional factors and work-family conflict on job satisfaction among single mother employees. American Journal of Applied Sciences, 8(11), 1107-1115.

[3] Ahmad, A., \& Omar, Z. (2010). Perceived workplace culture as an antecedent of job stress: The mediating role of work-family conflict. Journal of Social Sciences, 6(3), 369-375.

[4] Ahuja, M. K., Chudoba, K. M., Kacmar, C. J., McKnight, D. H., \& George, J. F. (2007). IT road warriors: Balancing work-family conflict, job autonomy, and work overload to mitigate turnover intentions. MIS Quarterly, 31(1), 1-17.

[5] Alam, M. S., Sattar, A., \& Chaudhury, S. N. (2011). Work family conflict of women managers in Dhaka. Asian Social Science, 7(7), 108-114.

[6] Albertsen, K., Rafnsdóttir, G. L., Grimsmo, A., Tómasson, K., \& Kauppinen, K. (2008). Workhours and worklife balance. Scandinavian Journal of Work, Environment \& Health, 34(5), 14-21.

[7] Anafarta, N. (2011). The relationship between work-family conflict and job satisfaction: A structural equation modeling (SEM) approach. International Journal of Business and Management, 6(4), 168-177.

[8] Anafarta, N., \& Kuruüzüm, A. (2012). Demographic predictors of work-family conflict for men and women: Turkish case. International Journal of Business and Management, $7(13), 145-158$.

[9] Ashfaq, S., Mahmood, Z., \& Ahmad, M. (2013). Impact of Work-Life Conflict and Work over Load on Employee Performance in Banking Sector of Pakistan. Middle-East Journal of Scientific Research, 14(5), 688-695.

[10] Aslam, R., Shumaila, S., Azhar, M., \& Sadaqat, S. (2011). Work-family conflicts: Relationship between work-life conflict and employee retention-A comparative study of public and private sector employees. Interdisciplinary Journal of Research in Business, 1(2), 18-29. 
[11] Beauregard, A. T. (2006). Are Organizations shooting themselves in the foot? Work place contribution to family-to-work conflict. Equal Opportunities International, 25(5), 336-353.

[12] Blanch, A., \& Aluja, A. (2009). Work, family and personality: A study of work-family conflict. Personality and Individual Differences, 46(4), 520-524.

[13] Carlson, D., Ferguson, M., Hunter, E., \& Whitten, D. (2012). Abusive supervision and work-family conflict: The path through emotional labor and burnout. The Leadership Quarterly, 23(5), 849-859.

[14] Cortese, C. G., Colombo, L., \& Ghislieri, C. (2010). Determinants of nurses' job satisfaction: the role of work-family conflict, job demand, emotional charge and social support. Journal of Nursing Management, 18(1), 35-43.

[15] Cronbach, L. J. (1951). Coefficient alpha and the internal structure of tests. Psychometrika, 6(3), 297-334.

[16] Examining the relationship of work-family conflict to job and life satisfaction: A case of hotel sales managers. International Journal of Hospitality Management, 30(1), 4654.

[17] Ghayyur, M., \& Jamal. W. (2012). Work-family conflicts: A case of employees' turnover intention. International Journal of Social Science and Humanity, 2(3), 168174.

[18] Gordon, M. (1998). A Dictionary of Sociology. Oxford, UK: Oxford University Press

[19] Grandey, A., Cordeiro, B., \& Crouter, A. (2005). A longitudinal and multi-source test of the work-family conflict and job satisfaction relationship. Journal of occupational and organizational psychology, 78(3), 305-323.

[20] Greenhaus, J. H., \& Beutell, N. J. (1985). Sources of conflict between work and family roles. Academy of Management Review, 10, 76-88.

[21] Hammer, L. B., Kossek, E. E., Yragui, N. L., Bodner, T. E., \& Hanson, G. C. (2009). Development and validation of a multidimensional measure of family supportive supervisor behaviors (FSSB). Journal of Management, 35(4), 837-856.

[22] Hinton, P., Brownlow, C., \& McMurray, I. (2004). SPSS explained. London, UK: Routledge.

[23] Ismail, A., Farihana Suhaimi, F., Bakar, R. A., \& Abu Bakar, M. A. (2012). The role of organizational humanistic social support in decreasing the interference of work problems on employees' family conflict. Acta Universitatis Danubius. Economica, $9(1), 5-20$.

[24] Knecht, M. K., Bauer, G. F., Gutzwiller, F., \& Hämmig, O. (2011). Persistent work-life conflict and health satisfaction-A representative longitudinal study in Switzerland. BMC Public Health, 11(1), 271-289.

[25] Koekemoer, F. E., \& Steyl, J. M. E. (2011). Conflict between work and nonwork roles of employees in the mining industry: Prevalence and differences between demographic groups. SA Journal of Human Resource Management, 9(1), 1-14.

[26] Komarraju, M. (2006). Work-family conflict and sources of support amongst Malaysian dual-career employees. Asian Academy of Management Journal, 11(1), 83-96. 
[27] Kossek, E. E., \& Lambert, S. (2005). Work-family scholarship: Voice and context. In E. E. Kossek \& S. Lambert (Eds.), Work and life integration: Organizational, cultural and individual perspectives (pp. 3-18). Mahwah, NJ: Lawrence Erlbaum.

[28] Lambert, E. G., \& Hogan, N. L. (2010). Work-family conflict and job burnout among correctional staff. Psychological reports, 106(1), 19-26.

[29] Lizano, E. L., \& Mor Barak, M. E. (2012). Workplace demands and resources as antecedents of job burnout among public child welfare workers: A longitudinal study. Children and Youth Services Review. 34(9), 1769-1776.

[30] Malik, M. I., Zaheer, A., Khan, M.A., and Ahmad, M. (2010). Developing and testing a model of burnout at work and turnover intensions among doctors in Pakistan. International Journal of Business and Management, 5(10): 234-247.

[31] Maslach, C., \& Jackson, S. E. (1981). The measurement of experienced burnout. Journal of Organizational Behavior, 2(2), 99-113.

[32] Montgomery, A. J., Panagopolou, E., \& Benos, A. (2006). Work-family interference as a mediator between job demands and job burnout among doctors. Stress and Health, 22(3), 203-212.

[33] Nadeem, M. S., \& Abbas, Q. (2009). The impact of work life conflict on job satisfactions of employees in Pakistan. International Journal of Business and Management, 4(5), 63-83.

[34] Namayandeh, H., Juhari, R., \& Yaacob, S. N. (2011). The effect of job satisfaction and family satisfaction on work-family conflict (w-fc) and family-work conflict (f-wc) among married female nurses in Shiraz-Iran. Asian Social Science, 7(2), 88-95.

[35] Neal, M. B., \& Hammer, L. B. (2007). Working couples caring for children and aging parents: Effects on work and well-being. Mahwah, NJ: Lawrence Erlbaum.

[36] Netemeyer RG, Boles JS, McMurrian R: Development and validation of work-family conflict and family-work conflict scales. J Appl Psychol 1996, 81(4); 400-410.

[37] Netemeyer, R. G., Maxham III, J. G., \& Pullig, C. (2005). Conflicts in the work-family interface: links to job stress, customer service employee performance, and customer purchase intent. Journal of Marketing, 69(2), 130-143.

[38] Ngah, N., Ahmad, A., \& Baba, M. (2009). The mediating effect of work-family conflict on the relationship between locus of control and job satisfaction. Journal of Social Sciences, 5(4), 348-354.

[39] Noor, S., \&Maad, N. (2008). Examining the relationship between work life conflict, stress and turnover intentions among marketing executives in Pakistan. International Journal of Business and Management, 3(11), 93-102.

[40] Patel, C. J., Govender, V., Paruk, Z., \& Ramgoon, S. (2006). Working mothers: Familywork conflict, job performance and family/work variables. SA Journal of Industrial Psychology, 32(2), 39-45.

[41] Sao, R. (2012). Work Life Balance in Today's World: A Necessitate for All. Indian Streams Research Journal, 2(1), 1-4.

[42] Sharafi, T \& Shahrokh, Z. (2012). The relationship between family-to-work conflict of employee and co-workers' turnover intention. Management Science Letters, 2(1), 1-10. 
[43] Tabassum, A. (2012). The impact of social support on work-to-family and family-towork conflict: An analysis on the female primary school teachers of Bangladesh. International Journal of Research Studies in Management, 1(2), 67-78.

[44] ten Brummelhuis, L. L., van der Lippe, T., Kluwer, E. S., \& Flap, H. (2008). Positive and negative effects of family involvement on work-related burnout. Journal of Vocational Behavior, 73(3), 387-396.

[45] Thanacoody, P. R., Bartram, T., \& Casimir, G. (2009). The effects of burnout and supervisory social support on the relationship between work-family conflict and intention to leave: A study of Australian cancer workers. Journal of health organization and management, 23(1), 53-69.

[46] Wang, Y., Chang, Y., Fu, J., \& Wang, L. (2012). Work-family conflict and burnout among Chinese female nurses: the mediating effect of psychological capital. $B M C$ Public Health, 12(1), 915-922.

[47] Witt, L. A., \& Carlson, D. S. (2006). The work-family interface and job performance: moderating effects of conscientiousness and perceived organizational support. Journal of Occupational Health Psychology, 11(4), 343-357.

[48] Zhang, J., \& Liu, Y. (2010). Antecedents of work-family conflict: Review and prospect. International Journal of Business and Management, 6(1), 89-103. 